\title{
Brief Discussion on Significance of Rules for Children to Strengthen Occupational Cultivation of Secretary
}

\author{
Xingji Li \\ Hezhou University, Hezhou, 542899, China
}

Keywords: Rules for Children, Secretary, Occupational cultivation

\begin{abstract}
Rules for Children was a regulated book for ignorant children in ancient China, which specifically regulated the "children" in terms of living, traveling outside, the way of dealing with people and learning. It will be quite significant for the present secretaries to further occupational cultivation if they can carry out relevant regulations of Rules for Children and this is reflected in the following: 1 . serve the leaders better and play the role of consultant; 2 . learn to behave well and have good quality; and 3. effectively contact and communicate with the outside and display a good secretary image.
\end{abstract}

\section{Introduction}

Rules for Children ${ }^{[1]}$ was a regulated book for ignorant compiled by scholar Li Yuxiu during the period of Emperor Kangxi in the Qing Dynasty, and formerly named Xun Meng Wen; during the period of Emperor Qianlong, scholar Jia Cunren modified it from form to contents and changed to its current name. this book analyzed the principles in the sentences "Young people should be filial to their parents at home and respectful to their brothers when they are with them. They should be serious and trustworthy, love the populace extensively and be close to those who are humane. When all this is done and there is time for other things, they should use it for the study of the classics" meticulously. As a part of "children", the secretaries at present can form a good occupational cultivation if they can selectively implement some rules in Rules for Children, and this will be significant to perform their duties well, serve themselves and others.

\section{Serve the leaders well and play the role of consultant}

The most important duty of secretary is to serve the leaders well, act as a consultant and ensure that the leaders are satisfied to the work done. But how to make the leaders satisfied? Rules for Children can get some enlightenments.

As stated in Filial at Home, "Respond to parents' request rapidly and do not be lazy to obey parents' orders". For a secretary, the leaders are equal to parents, therefore, if a secretary can obey the leaders' calling and order like treating parents, he/she will be recognized by the leaders and makes the leaders satisfied. As an important assistant and consultant of the leaders, secretary should deal with various daily transaction work in a careful and responsible manner and deal with relevant matters delivered by the leaders rapidly. Especially when dealing with some emergencies, secretary should form a problem solution rapidly within the shortest time, report it to the leaders for decision making, so as to avoid delaying important matters and serious consequence.

The work of secretary is very tedious, so it is difficult to avoid fault and even mistakes. At this time, the leader might criticize and blame the secretary for not fully understanding the situation. How should a secretary deal with criticism and blame? As stated in Filial at Home, "Listen to parents' edification and correspond to parents' responsibilities". A secretary should also correctly deal with the criticism and blame of leaders, and accept them in a respected manner, so that the leader will feel smooth internally, the secretary should not argue on the basis for reason in a resisting attitude and contradict the leader rudely, this will only make the leader feel that he is not respected, so that he will repel and even hate the secretary. On the contrary, if the secretary listens to the leader's criticism and makes a detailed report after the leader becomes calm and request the leader to judge the matters himself, the leader will feel that the secretary is not only thoughtful, but is also proper to deal with 
things, and will increase the good feeling to the secretary, and in the future, the leader will treat the secretary in a tolerance attitude, and this will bring great convenience to the work of secretary. Sometimes, the leader also might have fault and even mistakes, how should a secretary deal with it? As stated in Filial at Home, "if parents have fault, children should advise them in a sincere manner and soft sound. If parents do not listen to the advice, wait patiently, and continue if there is an opportunity, for example, when the parents have good mood or are happy; if parents still do not accept and even become angry, although children are sad to tears, they should still advise parents to make correction; even if they are blamed and beaten, they should not be regretful”. Similarly, when the leader ha fault and even mistake in work, the secretary should point it out timely so that the leader can make correction in case of serious subsequence and damage of leader's image. When pointing out the leader's fault, the secretary should be sincere with a smooth tone, so that the leader will not feel embarrassed, and that the leader can accept the secretary's advice calmly. Some leaders are also pretentious and stubborn, and they are generally unwilling to accept the secretary's opinion on their fault in work. For such leaders, the secretary should advise them repeatedly when they are happy, until the leaders realize their mistakes and modify them. In the process of advising, it is unavoidable that the leaders will misunderstand, say some words unpleasant to hear and do something out of the line, and the secretary should not care about it. When all misunderstandings are clarified, the leaders will correct their mistakes and change the crude attitude, and also will concern the secretary's secretary and provide due convenience for his/her work. As the saying goes "suffering is a blessing". A secretary with these qualities will be inevitably appreciated and concerned by leaders, with limitless prospect.

\section{Learn to behave well and have good quality}

A secretary should behave well first, because behavior is the precondition of deed, to do a thing well, it is required to behave well. As stated in Filial at Home, "Tell the parents when going out and notify them after returning; the living place should be fixed and work should not be changed at will; even if it is a tiny thing, do not act arbitrarily without telling parents; acting arbitrarily is easy to make mistakes; although the thing is very small, do not hide it behind parents' back, once it is found, parents will be sad." For the secretary work, the secretary is required to ask for instructions from and report to the secretary and adhere to the work post; do not act arbitrarily in case of anything; form the quality of distinguishing public from private interest and do not take the public goods. In actual life, some people act as the secretary for a long time and have an increasingly close relation with the leadership, so they are easy to forget their status, are offside when encountering things, issue orders on behalf of leaders and request the leaders to undertake adverse subsequence, which damages the leader's image. Some people are lack of organization discipline after acting as the secretary for a long time, and like to leave post to do other things at will, which finally causes that the due work is delayed. Some other secretaries take small things home, thinking that this will not cause loss to the public. What's worse, some secretaries assign tasks to relevant, seek for properties and occupy them in the name of leader. Such behaviors do not only ignore the existence of leaders, but also cause serious influence on the leader, unit and society, causing serious effect and even irreparable loss. Such secretaries do not behave well. If a leader has such a secretary, the result will be inevitably disastrous. On the contrary, if a secretary can examine himself/herself according to the requirements of Rules for Children, he will really relieve worry for leaders and his/her cultivation will also be strengthened gradually.

A secretary learning to behave always puts the leader in the first position, and in addition to thinking for the leaders and correctly comprehending and conveying the leader's instruction, he specially pays attention to the details. As stated in Respectful to Brothers, "ask the senior to be first during dinning or walking", "if the senior stands, the junior should not sit, and only after the senior sits down can the junior sit down”. At the time of dinning, or sitting or walking, the senior should be first before the junior; if the senior stands, the junior cannot sit down, and the junior can sit down only after the senior asks him to sit down. These details, if not emphasized, will not affect the whole, but are the performance of lacking of cultivation. A secretary stays together with the leader for a long 
time, cannot ignore the details. During dinning, the secretary should take drinking and food for the secretary, and at any occasion, ask the leader to be sit down and leave first; when the leader stands or assigns work, the secretary should stand to listen to the order; when the secretary arrives at a place together with the leader, he/she should sit beside the leader, and the secretary can be seated only after the leader sits down and ask him/her to be seated. Paying attention to these details does not mean to flatter the leader, but is to show due respect to the leader.

Sometimes, the leader will call another person who is not secretary, how should the secretary should do? As stated in Respectful to Brothers, "when the senior calls a person, the junior should call such person on behalf of the senior, if the person is absent, the junior should listen to the advice of the senior". By reference to this regulation, when the leader calls another person who is not secretary the secretary should call such person on behalf of the leader, if that person is absent, he/she should listen to the advice of the leader. This can reflect the secretary's quality of working actively and positively and flexibly dealing with the emergency. Sometimes, when a secretary meets a person who is not his/her direct leader, how should he/she do? As stated in Respectful to Brothers, "When meeting a senior, one should welcome him rapidly, if the senior does not speak, stand beside him and wait patiently; when greeting with him, lower the sound, but it should not be too low, otherwise, the senior will not hear". A secretary represents the image of the leader served. Even if the secretary meets a person who is not his/her direct leader, he/she should also greet with such person and treat him/her respectfully. We should remember that ways are always there, if such a person becomes the direct leader one day, and assume that he/she mentions this to the direct leader of the secretary, the secretary's performance of due cultivation both saves face for himself/herself and for the leader.

\section{Contact with the outside world}

In a sense, secretary is a window image, and a hub connecting the superior and subordinate and internal and external interconnection, so there must be communication and contact with the outside world naturally. Therefore, the secretary should pay attention to relevant etiquette (including look, appearance and gestures) to maintain the leader's image, display good service awareness and reflect the due occupational sprit, so as to communicate and contact with the external world efficiently.

In terms of look, the secretary should be generous, steadfast, dignified, and give others a feeling of comfort, safety and appetency. Especially when treating the old people, the secretary should be polite, so that the person treated will feel warm. As stated in Respectful to Brothers, "Do not call the senior name, be modest, and do not show off ability", "treat uncles like father, and treat cousins like own brothers and sisters." A secretary should not put on airs when meeting the old people, and should not call the other side's name by believing that he/she is superior to the other side. If a secretary should do so, although the other side will not say anything, he/she will feel uncomfortable internally, and thinks that the secretary is not well educated. Once such a feeling is formed, not only the secretary's image will be reduced, but for the direct leader, there will also be unexpected inconvenience. The correct treatment is that the secretary should treat the senior like his/her father and brother, receive the senior with smiling face and gentle attitude, communicate with the other side with polite wording and make the other side feel his/her good occupational cultivation, so as to get the cognition or praise of the other side, and complete the communication happily.

In terms of appearance, the secretary should be dressed appropriately. In many times, the appropriate dressing cannot only shape a good occupational image, give others a sense of good feeling and help to complete the communication smoothly. As stated in the chapter Caution, "wear the hat straightly, tie button well, wear socks and shoes suitably; clothes should be clean but not luxurious and the matching should be appropriate.” As s special occupation, the secretary should pay attention to dressing in different occasions. Overall, the dressing can be divided into occupational dressing, formal dress and leisure dress, in which "formal dress is used to attend the formal, grand and serious occasion; occupational dressing is the common dressing in modern occupational field, with consideration in stable tone, considerable fabric and regulated style; leisure dress is used for the

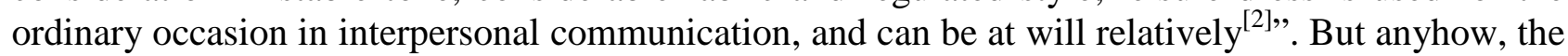
dressing of a secretary should always be suitable for his/her status, and should display the 


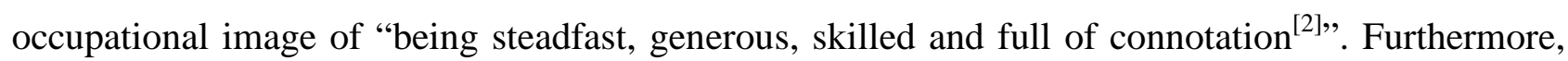
secretary should also purchase clothes according to the actual family economic condition, and cannot be extravagant to bring burden to family. In this way, the secretary can complete the work delivered by the leader smoothly with a pleasant attitude, good occupational image and flavor.

In terms of gesture, the secretary should pay attention to the gestures of sitting, standing and walking and act properly to reflect his/her behavioral cultivation and increase personal charm. As stated in the chapter Caution, "Be calm and steadfast and do not hurry during walking, stand grandly, keep head up, full of energy", these regulations require a person "to be proper in sitting and standing”, and reflect the sense of steadfastness, dignity through standing, and should not give a sense of frivolity and arbitrary.

In actual life, some secretaries are in a flurry, act hastily, not only giving a sense of being panic and unreliable, but also easy to make mistakes in flurry. As stated in the chapter Caution, "do not act in hurry, because it is easy to make mistakes in flurry, it is required to proceed steadfastly according to the steps", "be gentle when opening and closing doors", "be prudent when taking things as if they are full”. By reference to these regulations, a secretary should not be in a flurry when meeting things, but should be steadfast, and treat according to the steps. When entering the leader's room, knock at the door gently and do not make sound to avoid influencing the leader's work; when turning in the room, make a large turn, do not touch the corner and projection in case of unnecessary pain and disturbing the leaders. When taking empty things, take it as if it is full, and do not sway at will to make unnecessary sound. Even if the secretary knows that the leader is not in the room, if he/she needs to enter the leader's room for something, he/she should also keep revered as if the leader is in the room. Implementing these regulations can shape the secretary's image of being steadfast and grand, and reflect good cultivation in every behavior.

Sometimes, the secretary should pay attention to the details specially when communicating and contacting in other departments or units. As stated in the chapter Caution, "Before entering the room, ask if there is anybody in and express intention loudly", "if somebody asks, answer with name and let others know" The enlightenment to the secretary is that before entering the gate of a unit (or department), first ask whether somebody is in via the safeguard (or duty personnel), when coming to someone's office, express the intention loudly; when someone asks for the status, answer with name, but not "me", because answering with "me" will make the other side not clear who the secretary is, and might refuse to see him/her, and this will further bring barrier to the secretary's work. Paying attention to these details, not only the secretary is dignified and impressive, but the intention is also clear, so that the secretary's image can be maintained, and his/her cultivation is also reflected, and relevant communication and contact can also be carried out smoothly, just as the saying goes, "details decide success or failure".

As stated above, if a secretary can implement relevant regulations in Rules for Children, restrict his/her speech and behavior, he will inevitably strengthen his/her occupational cultivation, display his/her due spiritual favor and form his/her unique personality. On this basis, carrying out work actively and optimistically and serving the leader and other better, the secretary cannot only make success in various work, but also can reflect his/her value as a secretary.

\section{References}

[1] Translated by Li Yian, Three Character Classic, Hundred Family Surnames, Thousand Character Classic, Rules for Children, Zhonghua Book Company, 2009 edition

[2] Basic contents of secretary's code of conduct http: // zhidao . baidu . com/ link ? url= IvaP PTX pvzlW9opW5XNMEtSi9QzTvoM6rBEi1y6DP57JVlpdb9n0HnU3DqN8rwU6GRUaCAJ-qpzK TGPuemkpD_ 